\title{
A comprehensive understanding of structure and site occupancy of $Y$ in Y-doped BaZrO_3
}

\section{$\operatorname{AUTHOR}(\mathrm{S}):$}

Han, Donglin; Kishida, Kyosuke; Shinoda, Kozo; Inui, Haruyuki; Uda, Tetsuya

\section{CITATION:}

Han, Donglin ...[et al]. A comprehensive understanding of structure and site occupancy of Y in Y-doped BaZrO_3. Journal of Materials Chemistry A 2013, 1(9): 3027-3033

\section{ISSUE DATE:}

2013-01-07

URL:

http://hdl.handle.net/2433/191005

\section{RIGHT:}

This journal is (C) The Royal Society of Chemistry 2013; この論文は出版 社版でありません。引用の際には出版社版をご確認ご利用ください。; This is not the published version. Please cite only the published version. 
To: Journal of Material Chemistry A

A Comprehensive Understanding of Structure and Site Occupancy of Y in Y-Doped $\mathrm{BaZrO}_{3}$

Donglin Han ${ }^{\text {a }}$, Kyosuke Kishida ${ }^{\text {a }}$, Kozo Shinoda ${ }^{\text {, }}$, Haruyuki Inui ${ }^{\text {a }}$, Tetsuya Uda ${ }^{\text {a,* }}$

${ }^{a}$ Department of Materials Science and Engineering, Kyoto University,

Yoshida Honmachi, Sakyo-ku, Kyoto 606-8501, Japan

b Institute of Multidisciplinary Research for Advanced Materials, Tohoku University,

Katahira 2-1-1, Aoba-ku, Sendai 980-8577, Japan

*Corresponding author: materials_process@aqua.mtl.kyoto-u.ac.jp

TEL: +81-75-753-5445, FAX: +81-75-753-5284

Abstract:

Y-doped $\mathrm{BaZrO}_{3}(\mathrm{BZY})$ is of the perovskite structure $\left(\mathrm{ABO}_{3}\right)$, and is promising as an electrolyte in protonic ceramic fuel cells (PCFCs). However, factors limiting its protonic conductivity have not been clarified entirely, such as the unclear site occupancy of Y. In this work, X-ray diffraction patterns were collected utilizing synchrotron radiation with an incident energy close to energy of the 
Y K absorption edge. Therefore, precise Rietveld refinement was performed to determine the site occupancy of $\mathrm{Y}$ by the anomalous dispersion effect. The results revealed that for the stoichiometric sample of $\mathrm{BaZr}_{0.8} \mathrm{Y}_{0.2} \mathrm{O}_{3-\delta}, \mathrm{Y}$ only occupied the B-site. But in the Ba-deficient sample of $\mathrm{Ba}_{0.9} \mathrm{Zr}_{0.8} \mathrm{Y}_{0.2} \mathrm{O}_{3-\delta}$, two perovskite phases with different compositions were observed. In one $\mathrm{Y}$-poor phase, all Y occupied the B-site, while in another greatly Y-rich and Ba-deficient phase, Y was found to occupy both A and B-sites. These results clearly indicate the tendency towards A-site occupation of Y with an increasing Ba-deficiency.

Keywords: proton conductor, yttrium-doped barium zirconate, synchrotron radiation, anomalous dispersion effect

1. Introduction

After the discovery of proton conduction in acceptor-doped $\mathrm{SrCeO}_{3}$ by Iwahara et al. in the 1980 s [1, 2], research on proton conductive perovskite-type oxides $\left(\mathrm{ABO}_{3}\right)$ has been focused on for decades due to their high potential for use in electrochemical applications in an intermediate temperature range $\left(450-700{ }^{\circ} \mathrm{C}\right)$, such as an electrolyte for protonic ceramic fuel cells (PCFCs) [3]. Y-doped $\mathrm{BaZrO}_{3}(\mathrm{BZY})$ is one of the most promising candidates because of its high protonic conductivity in humid atmospheres [4 - 6], and significant stability against reaction with $\mathrm{CO}_{2}[7,8]$. Conventionally speaking, trivalent $\mathrm{Y}$ cations prefer B-site occupation to substitute tetravalent $\mathrm{Zr}$ cations, but the cationic radius intermediate between those of a $\mathrm{Zr}$ cation and a divalent $\mathrm{Ba}$ cation [9, 
10] has the possibility to make $\mathrm{Y}$ cations also available to substitute $\mathrm{Ba}$ cations in the A-site. However, the occupation of $\mathrm{Y}$ in different sites induces totally different reactions in defect chemistry; oxide ion vacancies are consumed or generated, depending on whether Y occupies the A or B-site. Decrease in oxide ion vacancies is detrimental to the dissociative absorption of water molecules into the lattice, resulting in a lower proton concentration [11]. Therefore, clarifying the site occupancy of Y in BZY is important, and several studies have already been conducted [12-14]. Yamazaki et al. [12] intentionally introduced Ba-deficiency into 20\% Y-doped $\mathrm{BaZrO}_{3}$, and reported decrease in conductivity and water content with increasing Ba-deficiency. They also found that up to a Ba-deficiency of 0.06, the system maintain a cubic perovskite structure without a precipitation of a second phase of zirconium-doped yttria. Azad et al. [13] used neutron diffraction for structural analysis, and observed two phases in $10 \%$ Y-doped $\mathrm{BaZrO}_{3}$. In one phase, $\mathrm{Y}$ cations partitioned over A and B-sites. Recently, Giannici et al. [14] conducted diffraction experiments using a synchrotron radiation facility. They confirmed no evidence of A-site occupation of Y cations by extended X-ray absorption fine structure (EXAFS) analysis and Raman spectroscopy for a stoichiometric sample. And until now, no general consensus has been achieved for this perennial debate on the site occupancy of Y in BZY.

In this work, synchrotron radiation with an incident energy close to Y-K absorption edge was applied to collect X-ray diffraction (XRD) patterns of stoichiometric and Ba-deficient BZY. With this specific incident energy, scattering factor differences between $\mathrm{Zr}$ and Y cations were significantly 
enlarged, enabling precise Rietveld refinement to determine the site occupancy of Y. In addition, scanning transmission electron microscopy (STEM) and energy dispersion X-ray spectroscopy (STEM-EDS) were utilized to observe microstructure and evaluate compositions, respectively. With these analyses, we established a more comprehensive understanding of the structure and site occupancy of Y in BZY.

\section{Experimental}

\subsection{Material preparation}

Samples were prepared by a conventional solid state reaction method. Nominal cation ratios of Ba : $\mathrm{Zr}: \mathrm{Y}$ of $1.0: 0.8: 0.2$ and $0.9: 0.8: 0.2$ were achieved by mixing the starting materials of $\mathrm{BaCO}_{3}$, $\mathrm{ZrO}_{2}$, and $\mathrm{Y}_{2} \mathrm{O}_{3}$ at the desired ratios. We subsequently named them as $\mathrm{BaZr}_{0.8} \mathrm{Y}_{0.2} \mathrm{O}_{3-\delta}$ and $\mathrm{Ba}_{0.9} \mathrm{Zr}_{0.8} \mathrm{Y}_{0.2} \mathrm{O}_{3-\delta}$ for convenience. $\quad$ Mixtures were ball-milled for $24 \mathrm{~h}$, and then pressed into pellets under 9.8 $\mathrm{MPa}$ and heat-treated at $1000{ }^{\circ} \mathrm{C}$ for $10 \mathrm{~h}$. After ball-milling for $10 \mathrm{~h}$, samples were pressed into pellets under 9.8 MPa again, and synthesized at $1300{ }^{\circ} \mathrm{C}$ for $10 \mathrm{~h}$. After that, samples were ball-milled for $24 \mathrm{~h}$ and mixed with an organic binder solution consisting of water, polyvinyl alcohol, glycerin, and ethanol. Mixtures were then pressed into pellets at $392 \mathrm{MPa}$, and subsequently heat-treated at $600{ }^{\circ} \mathrm{C}$ for $8 \mathrm{~h}$ to remove the binder solution. During sintering, pellets were initially heated to $1600{ }^{\circ} \mathrm{C}$ at a heating rate of $4{ }^{\circ} \mathrm{Cmin}^{-1}$ and kept for $24 \mathrm{~h}$, then furnace-cooled 
to room temperature. Pellets were then re-heated to $1600{ }^{\circ} \mathrm{C}$ at $4{ }^{\circ} \mathrm{Cmin}^{-1}$, and kept for $24 \mathrm{~h}$.

Finally, pellets were quenched to room temperature.

\subsection{Measurements}

Chemical compositions of the nominal compositions of $\mathrm{BaZr}_{0.8} \mathrm{Y}_{0.2} \mathrm{O}_{3-\delta}$ and $\mathrm{Ba}_{0.9} \mathrm{Zr}_{0.8} \mathrm{Y}_{0.2} \mathrm{O}_{3-\delta}$ were determined to be $\mathrm{Ba}_{0.97} \mathrm{Zr}_{0.81} \mathrm{Y}_{0.19} \mathrm{O}_{3-\delta}$ and $\mathrm{Ba}_{0.89} \mathrm{Zr}_{0.81} \mathrm{Y}_{0.19} \mathrm{O}_{3-\delta}$, respectively, by inductively coupled plasma atomic emission spectroscopy (ICP-AES) with SPS4000 (Seiko Instruments Inc., Japan). Microstructures were observed by scanning electron microscopy (SEM) and STEM with VE-7800 (Keyence Co., Japan) and JEM-2100F (JEOL, Japan), respectively. Samples for STEM observations were thinned by an argon ion $\left(\mathrm{Ar}^{+}\right)$beam using a JEOL EM-09100IS Ion Slicer. The local composition was identified by STEM-EDS with JEOL JED-2300.

Powder XRD analysis was performed at the SPring-8 synchrotron radiation facility (Hyogo, Japan) by using beamline BL19B2 with X-ray energies of $16.908 \mathrm{keV}$ and $17.026 \mathrm{keV}$. As shown in Figure 1, using X-ray with an energy near Y K-edge, a dramatic drop in the real part of anomalous dispersion terms in the X-ray atomic scattering factor, given in Eq. (1), of Y ( $f^{\prime}{ }_{Y}(E)$ ) occurs by the anomalous dispersion effect, and the difference between $f^{\prime}{ }_{\mathrm{Y}}(E)$ and $f_{\mathrm{Zr}}^{\prime}(E)$ increases.

$$
f_{n}=f_{n, 0}(\sin \theta / \lambda)+f^{\prime}{ }_{n}(E)+\mathrm{i} f^{\prime \prime}{ }_{n}(E)
$$

Therefore, the scattering factor difference between $\mathrm{Y}$ and $\mathrm{Zr}$ cations can be enhanced, and site occupancy of $\mathrm{Y}$ cations can be determined with better precision by Rietveld refinement. 
Refinement was performed using the commercial software TOPAS (Bruker AXS GmbH).

\section{Results}

\subsection{XRD analysis}

XRD patterns collected using X-ray with an energy of $17.026 \mathrm{keV}$ are shown in Figure 2. Profiles of (031) diffraction peaks are highlighted as an example. In the XRD pattern of $\mathrm{Ba}_{0.9} \mathrm{Zr}_{0.8} \mathrm{Y}_{0.2} \mathrm{O}_{3-\delta}$, in addition to a sharp major peak (peak 1), overlapping of a weak peak (peak 2) at the relatively high angle side is apparent (see Figure 2(a)). Such a phenomenon was also clearly confirmed for "all the peaks”, suggesting possible coexistence of two phases with the perovskite structure with different lattice constants, besides precipitation of $\mathrm{Y}_{2} \mathrm{O}_{3}$ solid solution. In the XRD pattern of $\mathrm{BaZr}_{0.8} \mathrm{Y}_{0.2} \mathrm{O}_{3-\delta}$, all peaks exhibited a small slope at "the low angle side" of the sharp major peak, as shown in the example of the (031) diffraction peak profile in the inset of Figure 2(b).

\subsection{Microstructure observation}

SEM images of fractured cross-sections of samples are shown in Figure 3. For the Ba-deficient sample, a bimodal microstructure was obtained as shown in Figure 3(a). A dense microstructure with a uniform grain size was obtained for the nominally stoichiometric sample of $\mathrm{BaZr}_{0.8} \mathrm{Y}_{0.2} \mathrm{O}_{3-\delta}$ (see Figure 3(b)). 


\subsection{Composition analysis by STEM-EDS}

Intra-grain compositions measured by STEM-EDS are plotted in Figure 4. Compositions tended to separate into two groups. One is major and close to the nominal composition, and another is greatly Y-rich and Ba-deficient. For discussion, we refer to the phases with these two different compositions as the major phase and minor phase, respectively. Since the probe size used for STEM-EDS analysis was about $1 \mathrm{~nm}$, local composition could be measured. It is important to indicate that these two phases were even observed in a single grain. In addition, we should mention that, in the $\mathrm{BaZr}_{0.8} \mathrm{Y}_{0.2} \mathrm{O}_{3-\delta}$ sample, the average composition of the major phase almost coincides with the nominal composition, but in the $\mathrm{Ba}_{0.9} \mathrm{Zr}_{0.8} \mathrm{Y}_{0.2} \mathrm{O}_{3-\delta}$ sample, the average value clearly deviates from the nominal composition. The average compositions of the major and minor phases of the $\mathrm{Ba}_{0.9} \mathrm{Zr}_{0.8} \mathrm{Y}_{0.2} \mathrm{O}_{3-\delta}$ sample were calculated to be $\mathrm{Ba}_{0.90} \mathrm{Zr}_{0.88} \mathrm{Y}_{0.12} \mathrm{O}_{3-\delta}$ and $\mathrm{Ba}_{0.74} \mathrm{Zr}_{0.55} \mathrm{Y}_{0.45} \mathrm{O}_{3-\delta}$, respectively.

The major perovskite XRD pattern in $\mathrm{Ba}_{0.9} \mathrm{Zr}_{0.8} \mathrm{Y}_{0.2} \mathrm{O}_{3-\delta}$ (Peak 1 in Figure 3(a)) can be attributed to the major phase, and the weak perovskite XRD pattern at the relatively high angle side (Peak 2 in Figure 3(a)) corresponds to the minor phase. For $\mathrm{BaZr}_{0.8} \mathrm{Y}_{0.2} \mathrm{O}_{3-\delta}$, the sharp main perovskite XRD pattern should be also attributed to the major phase. Since only little amount of the minor phase was confirmed in $\mathrm{BaZr}_{0.8} \mathrm{Y}_{0.2} \mathrm{O}_{3-\delta}$ during the STEM-EDS analysis, it is reasonable to conclude that diffraction peaks for the minor phase cannot be observed in the powder XRD pattern. We also considered the possibility that the minor phase may be attributed to the reported phenomenon of 
relatively a higher Y content around the grain boundary [15-18]. However, as shown in Figure 5, such a phenomenon was not confirmed by STEM-EDS in this study. The most difficult point in the interpretation of the XRD pattern of $\mathrm{BaZr}_{0.8} \mathrm{Y}_{0.2} \mathrm{O}_{3-\delta}$ is explaining the small slope at the relatively low angle side (see Figure 2(b)), but we got a conviction that this is due to the hydration of the sample recently [21], and explain it in the Rietveld refinement session.

\subsection{Rietveld refinement}

(a) $\mathrm{Ba}_{0.9} \mathrm{Zr}_{0.8} \mathrm{Y}_{0.2} \mathrm{O}_{3-\delta}$

Figure 6 shows the Rietveld refinement profile, using the average compositions by STEM-EDS, for the XRD pattern of $\mathrm{Ba}_{0.9} \mathrm{Zr}_{0.8} \mathrm{Y}_{0.2} \mathrm{O}_{3-\delta}$ collected using $\mathrm{X}$-ray with an energy of $17.026 \mathrm{keV}$. In addition to yttria, two cubic perovskite $(P m \overline{3} m)$ structure models were assumed for the major phase $\left(\mathrm{Ba}_{0.90} \mathrm{Zr}_{0.88} \mathrm{Y}_{0.12} \mathrm{O}_{3-\delta}\right)$ and minor phase $\left(\mathrm{Ba}_{0.74} \mathrm{Zr}_{0.55} \mathrm{Y}_{0.45} \mathrm{O}_{3-\delta}\right)$. Good quality for refinement was obtained with $R_{\mathrm{wp}}=6.15 \%$. The lattice constants and weight fractions of the phases are summarized in Table 1. About $7.0 \mathrm{wt} \%$ of yttria was determined, which is consistent with the results of Yamazaki et al. [12] As summarized in Table 2, in the phase with the composition of $\mathrm{Ba}_{0.90} \mathrm{Zr}_{0.88} \mathrm{Y}_{0.12} \mathrm{O}_{3-\delta}$, $\mathrm{Y}$ only occupied the B-site. In the greatly $\mathrm{Y}$-rich and Ba-deficient phase with the composition of $\mathrm{Ba}_{0.74} \mathrm{Zr}_{0.55} \mathrm{Y}_{0.45} \mathrm{O}_{3-\delta}$, $\mathrm{Y}$ was determined to occupy both $\mathrm{A}$ and B-sites. Results of the measurements using X-ray with an energy of $16.908 \mathrm{keV}$ are also given in Table 2, showing good consistency with those of $17.026 \mathrm{keV}$. 
(b) $\mathrm{BaZr}_{0.8} \mathrm{Y}_{0.2} \mathrm{O}_{3-\delta}$

It is obviously difficult to simulate the XRD pattern of $\mathrm{BaZr}_{0.8} \mathrm{Y}_{0.2} \mathrm{O}_{3-\delta}$ with a single perovskite cubic ( $P m \overline{3} m$ ) structure model. In fact, we could only obtain a large $R_{\mathrm{wp}}$ of $16.35 \%$, when assuming a single perovskite cubic structure model. Giannici et al. used a tetragonal perovskite-type (P4/mbm) structure model for the refinement of $15 \%$ Y-doped $\mathrm{BaZrO}_{3}$ [14]. However, this tetragonal model is also difficult to accept. For the diffraction peaks with three identical indices, such as (222) expressed in a cubic system, there should be no peak splitting, and the diffraction peak should be of good peak symmetry even in tetragonal model. However, as shown in Figure 7, the (222) diffraction peak was also poorly symmetric. Again, if we use the tetragonal perovskite-type ( $P 4 / \mathrm{mbm})$ structure model to simulate the diffraction profile, only a large value of $R_{\mathrm{wp}}$ of $17.62 \%$ is obtained. Therefore, the structure of $\mathrm{BaZr}_{0.8} \mathrm{Y}_{0.2} \mathrm{O}_{3-\delta}$ cannot be tetragonal.

In Ref. [21], it has been reported that the lattice of $\mathrm{BaZr}_{0.8} \mathrm{Y}_{0.2} \mathrm{O}_{3-\delta}$ expands by hydration, and lattice constants of hydrated and unhydrated samples are $4.2319 \AA$ and $4.2235 \AA$, respectively. For refinement of the XRD pattern of $\mathrm{BaZr}_{0.8} \mathrm{Y}_{0.2} \mathrm{O}_{3-\delta}$, we assumed that two cubic perovskite ( $P m \overline{3} m$ ) structure models both with the composition of $\mathrm{Ba}_{0.97} \mathrm{Zr}_{0.8} \mathrm{Y}_{0.2} \mathrm{O}_{3-\delta}$, a low value of $R_{\text {wp }}=7.17 \%$ could be obtained, as shown in Figure 8. The refined lattice constants of $4.2298 \AA$ and $4.2230 \AA$ for the two cubic models are comparable to those of hydrated and unhydrated $\mathrm{BaZr}_{0.8} \mathrm{Y}_{0.2} \mathrm{O}_{3-\delta}$. We thereby believe that a part of the sample measured by XRD analysis was hydrated. All Y was determined to be of B-site occupation, as expected, in this refinement. 


\section{Discussion}

As summarized in Table 2, the results of the Rietveld refinements by using powder XRD patterns collected with synchrotron radiation with the energies of $17.026 \mathrm{keV}$ and $16.908 \mathrm{keV}$ show good agreement. Low value of $R_{\mathrm{wp}}$ was obtained for all the refinements. For the sample with an intentionally introduced Ba-deficiency of 0.1 , coexistence of two phases with the cubic perovskite structure was confirmed, in addition to the precipitation of the $\mathrm{Y}_{2} \mathrm{O}_{3}$ solid solution. One phase has a relatively small lattice constant, with a high Y content of 0.45 and great Ba-deficiency. A part of the Y cations in this phase occupied the A-site. Another phase has a relatively large lattice constant, with all the Y cations occupying the B-site, which does not conflict with our previous work [19]. The coexistence of these two phases is also considered to be the cause of poor sinterability of this sample, as shown in Figure 3(a).

A tetragonal perovskite structure model was used to explain asymmetric diffraction peaks in stoichiometric samples in the literature $[14,20]$. However, as indicated in this study, for the nominally stoichiometric sample of $\mathrm{BaZr}_{0.8} \mathrm{Y}_{0.2} \mathrm{O}_{3-\delta}$, a better interpretation has been achieved by using two compositionally identical cubic models with different lattice constants resulting from a hydration effect. A schematic relationship of the lattice constants and compositions of the cubic perovskite structure models in this study is given in Figure 9.

It should be interesting to note that the coexistence of two compositionally different phases, especially in a single grain was observed. As summarized in Table 3, the observation in this work 
is in accordance with some previous reports. Oyama et al. [22] reported that a BZ(II) phase with long range order supercell and a composition between $\mathrm{Ba}_{3} \mathrm{Zr}_{2} \mathrm{YO}_{8.5}$ and $\mathrm{Ba}_{9} \mathrm{Zr}_{4} \mathrm{Y}_{8} \mathrm{O}_{19}$ existed in a slightly Ba-deficient sample. Imashuku et al. [23] found a phase (BZY424) with the cation ratio of Ba : Zr : Y about $4: 2: 4$ in composition. The compositions of their newly discovered phases are comparable to the greatly Y-rich phase of $\mathrm{Ba}_{0.74} \mathrm{Zr}_{0.55} \mathrm{Y}_{0.45} \mathrm{O}_{3-\delta}$, namely minor phase, in this study. In addition, as mentioned in introduction, Azad et al. [13] found two phases in $10 \%$ Y-doped $\mathrm{BaZrO}_{3}$. Although the compositions of these two phases were not directly measured, we considered that the phase ( $\alpha$ phase) with a small lattice constant might be similar with the minor phase in this study. However, as discussed in Ref. [21] in detail, hydration also expands the lattice of BZY, resulting in a very complicated situation. Further work will be devoted to the detailed discussion of this minor phase in the future.

This work reveals clearly that Ba-deficiency causes a separation to two phases with the perovskite structure, which must be considered to be detrimental to protonic conductivity, and is expected to be another possible reason for the decrease in protonic conductivity with increasing Ba-deficiency [12, 24].

6. Conclusions

Powder XRD patterns for $\mathrm{Ba}_{0.9} \mathrm{Zr}_{0.8} \mathrm{Y}_{0.2} \mathrm{O}_{3-\delta}$ indicate the coexistence of two phases with the cubic perovskite structure. By STEM-EDS, one is relatively low in Y content and slightly Ba-deficient, 
and another is greatly Ba-deficient and Y-rich. It is interesting that these two compositionally different phases were even observed in a single grain. However, for the nominally stoichiometric $\mathrm{BaZr}_{0.8} \mathrm{Y}_{0.2} \mathrm{O}_{3-\delta}$, a small slope was also observed at the low angle side in the diffraction pattern, which is believed to be due to lattice expansion for hydration [21]. By Rietveld refinement, Y was determined to only occupy the B-site in both the two phases in the nominally stoichiometric sample of $\mathrm{BaZr}_{0.8} \mathrm{Y}_{0.2} \mathrm{O}_{3-\delta}$. For the two perovskite phases in the nominally Ba-deficient sample of $\mathrm{Ba}_{0.9} \mathrm{Zr}_{0.8} \mathrm{Y}_{0.2} \mathrm{O}_{3-\delta}$, all $\mathrm{Y}$ occupied the $\mathrm{B}$-site in the relatively $\mathrm{Y}$-poor and Ba-deficient phase. However, a partial amount of Y occupied the A-site in the greatly Y-rich and Ba-deficient phase. The results indicate the tendency of Y towards A-site occupation with increasing Ba-deficiency and Y content.

\section{Acknowledgements}

This study was supported by the Industrial Technology Research Grant Program in 2006 from the New Energy and Industrial Technology Development Organization (NEDO) of Japan. Powder XRD analysis was performed at the SPring-8 synchrotron radiation facility (Hyogo, Japan) with the approval of the Japan Synchrotron Radiation Research Institute (JASRI) as industrial application proposal (No. 2010B1850). 


\section{References}

1 H. Iwahara, T. Esaka, H. Uchida and N. Maeda, Solid State Ion., 1981, 3-4, 359.

2 H. Iwahara, H. Uchida and S. Tanaka, Solid State Ion., 1983, 9-10, 1021.

3 W.G. Coors, J. Power Sources, 2003, 118, 150.

4 K.D. Kreuer, Annu. Rev. Mater. Res., 2003, 33, 333.

5 Y. Yamasaki, R. Hernandez-Sanchez and S.M. Haile, Chem. Mater., 2009, 21, 2755.

6 D. Pergolesi, E. Fabbri, A. D’Epifanio, E.D. Bartolomeo, A. Tebano, S. Sanna, S. Licoccia, G.

Balestrino and E. Traversa, Nat. Mater., 2010, 9, 846.

7 K. Katahira,Y. Kohchi, T. Shimura and H. Iwahara, Solid State Ion., 2000, 138, 91.

8 Y. Guo, Y. Lin, H. Shi, R. Ran and Z. Shao, Chin. J. Catal., 2009, 30, 479.

9 R. D. Shannon, Acta Crystallogr., Sect. A, 1976, 32, 751.

10 K. Park, C. Kim, Y. Yoon, S. Song, Y. Kim and K. Hur, J. Eur. Ceram. Soc., 2009, 29, 1735.

11 T. Norby, M. Widerøe, R. Glöckner and Y. Larring, Dalton Trans., 2004, 19, 3012.

12 Y. Yamazaki, R. Hernandez-Sanchez and S.M. Haile, J. Mater. Chem., 2010, 20, 8158.

13 A.K. Azad, C. Savaniu, S. Tao, S. Duval, P. Holtappels, R.M. Ibberson and J.T.S. Irvine, J. Mater. Chem. 2008, 18, 3414.

14 F. Giannici, M. Shirpour, A. Longo, A. Martorana, R. Merkle and J. Maier, Chem. Mater. 2011, 23, 2994.

15 R.B. Cervera, Y. Oyama, S. Miyoshi, K. Kobayashi, T. Yagi and S. Yamaguchi, Solid State Ion. 
2008, 179, 236.

16 F. Iguchi, T. Tsurui, N. Sata, Y. Nagao and H. Yugami, Solid State Ion., 2009, 180, 563.

17 S. Ricote, N. Bonanos, H.J. Wang and B.A. Boukamp, Solid State Ion., 2012, 213, 36.

18 M. Shirpour, R. Merkle and J. Maier, Solid State Ion., 2012, 255, 304.

19 D. Han, Y. Nose, K. Shinoda and T. Uda, Solid State Ion., 2012, 213, 2.

20 K.D Kreuer, St. Adams, W. Münch, A. Fuchs, U. Klock and J. Maier, Solid State Ion., 2001, 145, 295.

21 C. Hiraiwa, D. Han, A. Kuramitsu, A. Kuwabara, H. Takeuchi, M. Majima and T. Uda, J. Am. Ceram. Soc., DOI: 10.1111/jace.12172.

22 Y. Oyama, A. Kojima, X. Li, R.B. Cervera, K. Tanaka and S. Yamaguchi, Solid State Ion., 2011, 197, 1.

23 S. Imashuku, T. Uda, Y. Nose and Y. Awakura, J. Phase Equilib. Diff., 2010, 31, 348.

24 P. Babilo, T. Uda and S.M. Haile, J. Mater. Res., 2007, 22, 1322. 


\section{List of Captures}

Figure 1 Anomalous dispersion terms of $\mathrm{Y}$ (red profiles) and $\mathrm{Zr}$ (blue profiles). Differences in either $f_{n}^{\prime}(E)$ or $f_{n}^{\prime \prime}(E)$ between $\mathrm{Y}$ and $\mathrm{Zr}$ are small at an incident energy of $\mathrm{Cu} \mathrm{K \alpha}(8.04 \mathrm{keV})$. Dramatic decreases in $f_{\mathrm{Y}}^{\prime}(E)$ occurs when the incident energy approaches the $\mathrm{Y}$ K-edge (17.037 $\mathrm{keV})$, resulting in an increase in the difference in $f_{n}^{\prime}(E)$ between $\mathrm{Y}$ and $\mathrm{Zr}$.

Figure 2 X-ray diffraction patterns of (a) $\mathrm{Ba}_{0.9} \mathrm{Zr}_{0.8} \mathrm{Y}_{0.2} \mathrm{O}_{3-\delta}$ and (b) $\mathrm{BaZr}_{0.8} \mathrm{Y}_{0.2} \mathrm{O}_{3-\delta}$. diffraction peak profiles are highlighted in insets as an example.

Figure 3 SEM images of fractured cross-sections of (a) $\mathrm{Ba}_{0.9} \mathrm{Zr}_{0.8} \mathrm{Y}_{0.2} \mathrm{O}_{3-\delta}$, and (b) $\mathrm{BaZr}_{0.8} \mathrm{Y}_{0.2} \mathrm{O}_{3-\delta}$.

Figure 4 STEM-EDS composition analysis of $\mathrm{Ba}_{0.9} \mathrm{Zr}_{0.8} \mathrm{Y}_{0.2} \mathrm{O}_{3-\delta}(\bullet$ major phase, and $\circ$ minor phase $)$ and $\mathrm{BaZr}_{0.8} \mathrm{Y}_{0.2} \mathrm{O}_{3-\delta}$ ( $\boldsymbol{\Delta}$ major phase, and $\Delta$ minor phase). The nominal composition of $\mathrm{Ba}_{0.9} \mathrm{Zr}_{0.8} \mathrm{Y}_{0.2} \mathrm{O}_{3-\delta}(\bigotimes)$ and $\mathrm{BaZr}_{0.8} \mathrm{Y}_{0.2} \mathrm{O}_{3-\delta}(\star)$ are also plotted.

Figure 5 STEM-EDS line scan results of $\mathrm{BaZr}_{0.8} \mathrm{Y}_{0.2} \mathrm{O}_{3-\delta}$ across the grain boundary.

Figure 6 Rietveld refinement of the diffraction pattern of $\mathrm{Ba}_{0.9} \mathrm{Zr}_{0.8} \mathrm{Y}_{0.2} \mathrm{O}_{3-\delta}$, collected with synchrotron radiation $(17.026 \mathrm{keV})$. Two cubic perovskite ( $\mathrm{Pm} \overline{3} \mathrm{~m}$ ) structure models were adopted 
for the refinement. Fitting of the (031) diffraction peak profile is highlighted in the inset. The observed profile (blue), calculated profile (red), difference (black, at bottom), and Bragg peaks of candidate phases (vertical lines) are shown.

Figure 7 Rietveld refinement of the $(222)^{\mathrm{c}}$ diffraction peak of $\mathrm{BaZr}_{0.8} \mathrm{Y}_{0.2} \mathrm{O}_{3-\delta}$. $\quad(h k l)^{\mathrm{c}}$ indicates Miller indices in the cubic system. The diffraction pattern was collected with synchrotron radiation (17.026 keV). A single tetragonal perovskite $(P 4 / \mathrm{mbm})$ structure model was adopted for this refinement. The observed profile (blue), calculated profile (red), difference (black, at bottom), and Bragg peaks of candidate phases (vertical lines) are shown. The calculated profile is of good symmetry, and is obviously different from the observed profile.

Figure 8 Rietveld refinement of the diffraction pattern of $\mathrm{BaZr}_{0.8} \mathrm{Y}_{0.2} \mathrm{O}_{3-\delta}$, collected with synchrotron radiation $(17.026 \mathrm{keV})$. Two cubic perovskite $(P m \overline{3} \mathrm{~m})$ structure models were adopted for the refinement. Fitting of (031) diffraction peak profile is highlighted in the inset. Observed profile (blue), calculated profile (red), difference (black, at bottom), and Bragg peaks of candidate phases (vertical lines) are shown.

Figure 9 Summary of lattice constant and composition of the perovskite structure models in this study. 
Table 1 Lattice constants and weight fractions of phases in $\mathrm{Ba}_{0.9} \mathrm{Zr}_{0.8} \mathrm{Y}_{0.2} \mathrm{O}_{3-\delta}$ and $\mathrm{BaZr}_{0.8} \mathrm{Y}_{0.2} \mathrm{O}_{3-\delta}$ determined by Rietveld refinement.

Table 2 Site occupancy of cations in the phases in $\mathrm{Ba}_{0.9} \mathrm{Zr}_{0.8} \mathrm{Y}_{0.2} \mathrm{O}_{3-\delta}$ and $\mathrm{BaZr}_{0.8} \mathrm{Y}_{0.2} \mathrm{O}_{3-\delta}$ determined by Rietveld refinement. The structures of all the phases were assigned to be cubic ( $P m \overline{3} m$ ).

Table 3 Phases in $\mathrm{BaO}-\mathrm{ZrO}_{2}-\mathrm{YO}_{1.5}$ system in literatures. 


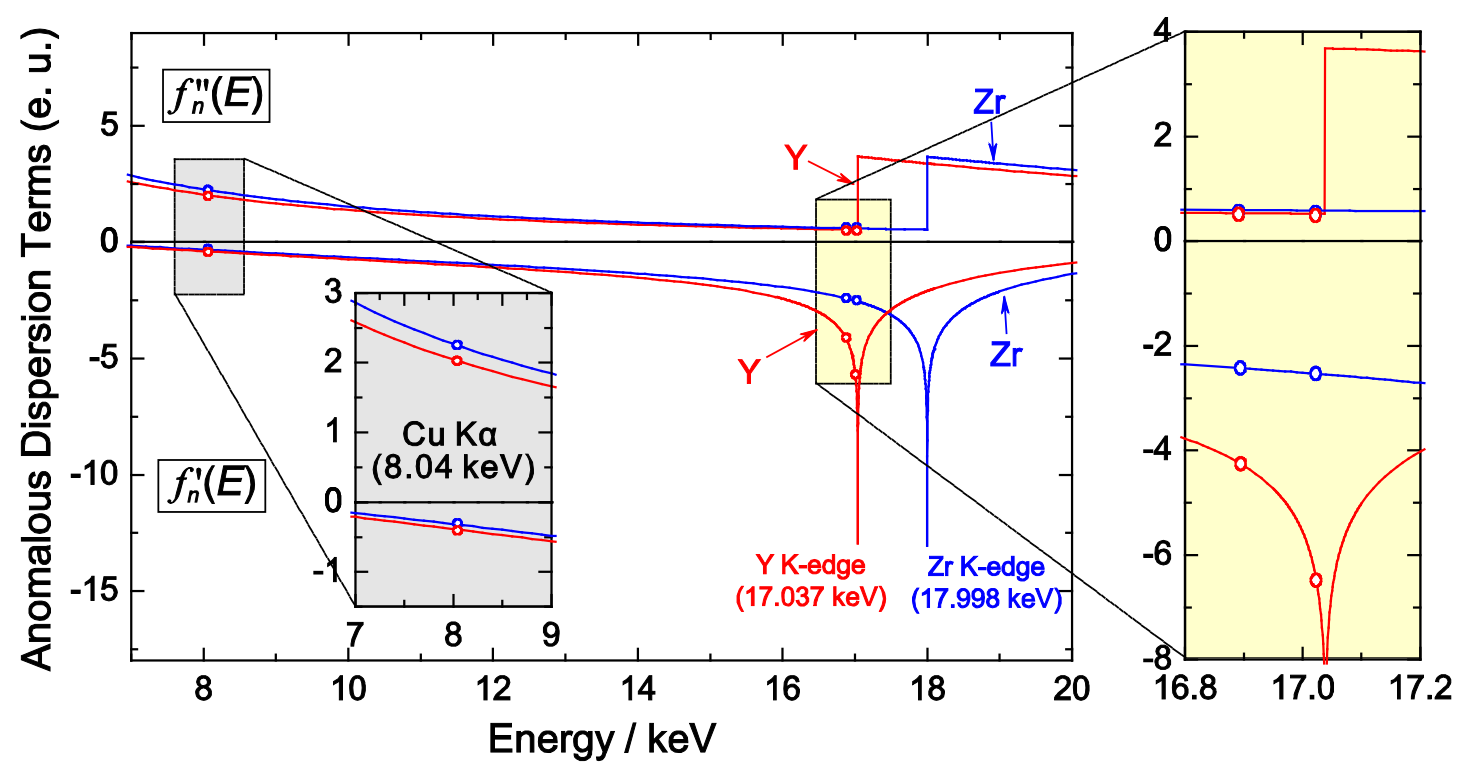

Figure 1 Anomalous dispersion terms of Y (red profiles) and Zr (blue profiles). Differences in either $f_{n}^{\prime}(E)$ or $f_{n}^{\prime \prime}(E)$ between $\mathrm{Y}$ and $\mathrm{Zr}$ are small at an incident energy of $\mathrm{Cu} \mathrm{K \alpha}(8.04 \mathrm{keV})$. Dramatic decreases in $f_{\mathrm{Y}}^{\prime}(E)$ occurs when the incident energy approaches the $\mathrm{Y}$ K-edge (17.037 $\mathrm{keV})$, resulting in an increase in the difference in $f_{n}^{\prime}(E)$ between $\mathrm{Y}$ and $\mathrm{Zr}$. 


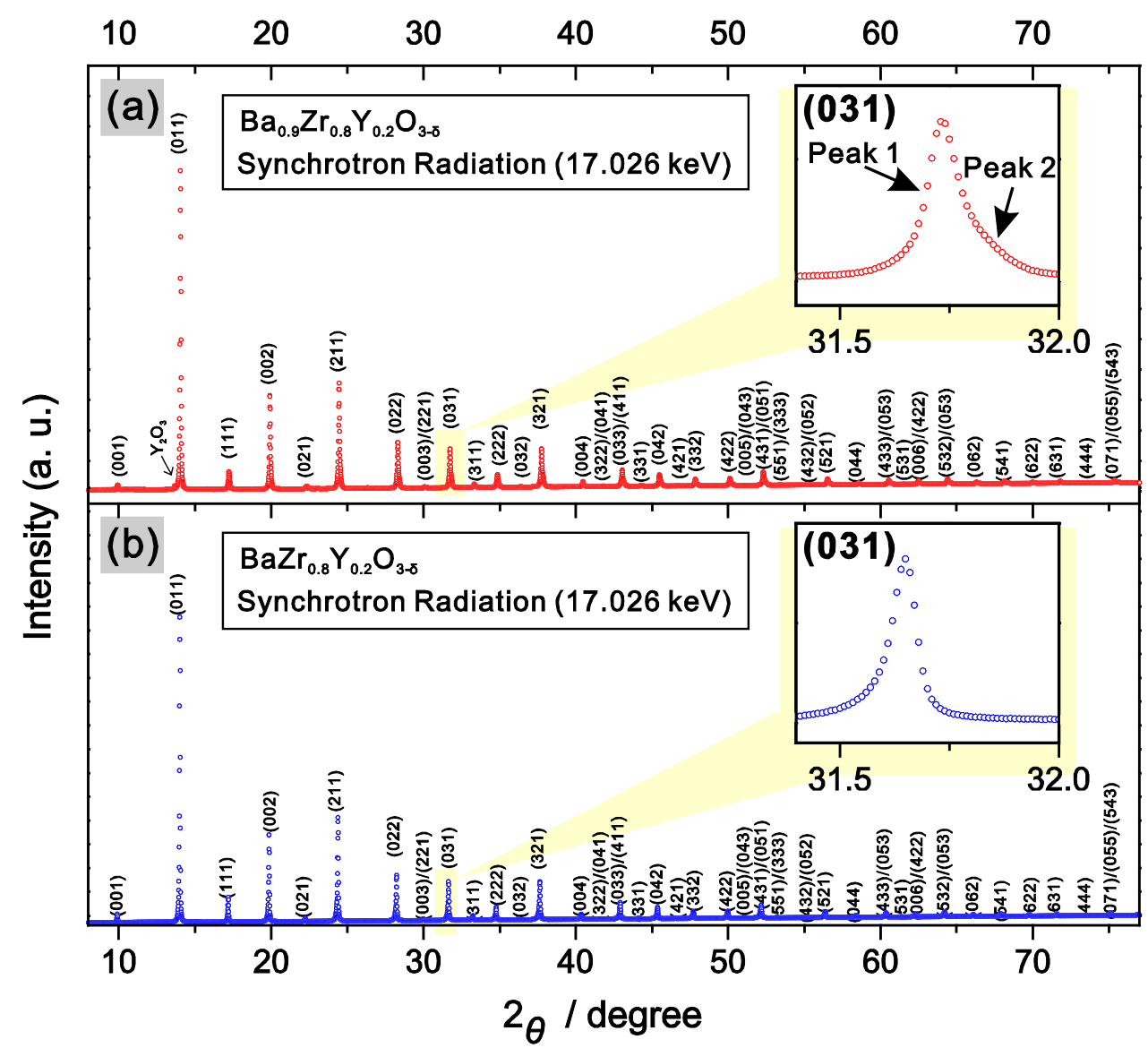

Figure 2 X-ray diffraction patterns of (a) $\mathrm{Ba}_{0.9} \mathrm{Zr}_{0.8} \mathrm{Y}_{0.2} \mathrm{O}_{3-\delta}$ and (b) $\mathrm{BaZr}_{0.8} \mathrm{Y}_{0.2} \mathrm{O}_{3-\delta}$. diffraction peak profiles are highlighted in insets as an example. 

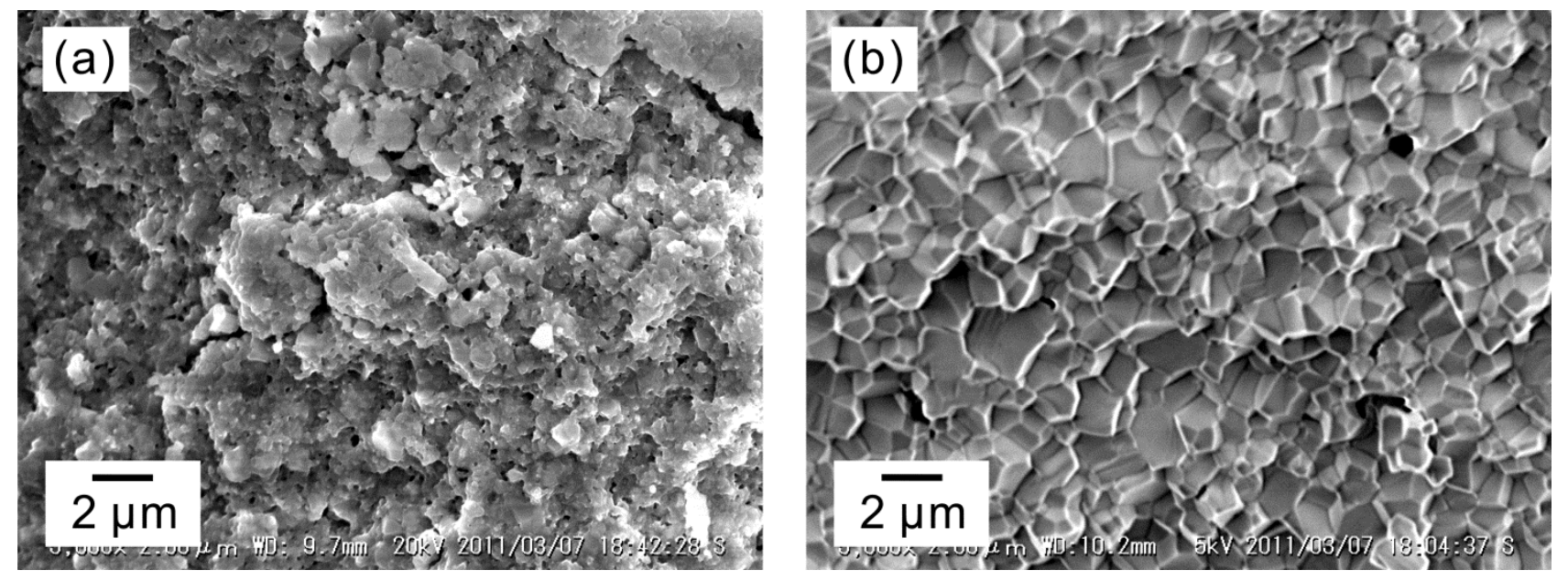

Figure 3 SEM images of fractured cross-sections of (a) $\mathrm{Ba}_{0.9} \mathrm{Zr}_{0.8} \mathrm{Y}_{0.2} \mathrm{O}_{3-\delta}$, and (b) $\mathrm{BaZr}_{0.8} \mathrm{Y}_{0.2} \mathrm{O}_{3-\delta}$. 


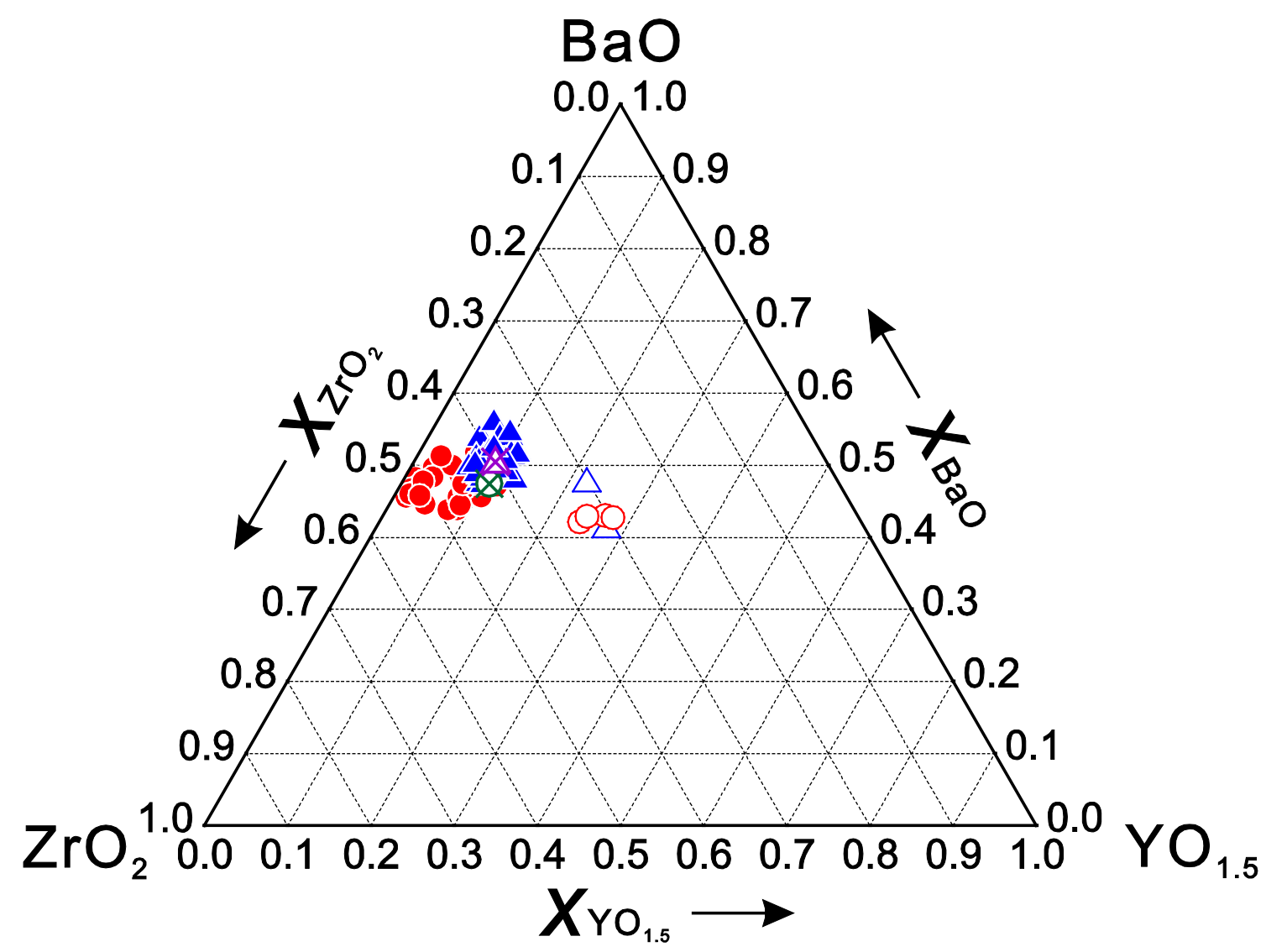

Figure 4 STEM-EDS composition analysis of $\mathrm{Ba}_{0.9} \mathrm{Zr}_{0.8} \mathrm{Y}_{0.2} \mathrm{O}_{3-\delta}(\bullet$ major phase, and $\circ$ minor phase) and $\mathrm{BaZr}_{0.8} \mathrm{Y}_{0.2} \mathrm{O}_{3-\delta}$ ( $\boldsymbol{\Delta}$ major phase, and $\triangle$ minor phase). The nominal composition of $\mathrm{Ba}_{0.9} \mathrm{Zr}_{0.8} \mathrm{Y}_{0.2} \mathrm{O}_{3-\delta}(\bigotimes)$ and $\mathrm{BaZr}_{0.8} \mathrm{Y}_{0.2} \mathrm{O}_{3-\delta}(\Downarrow)$ are also plotted. 


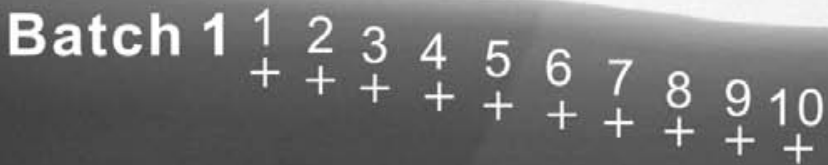

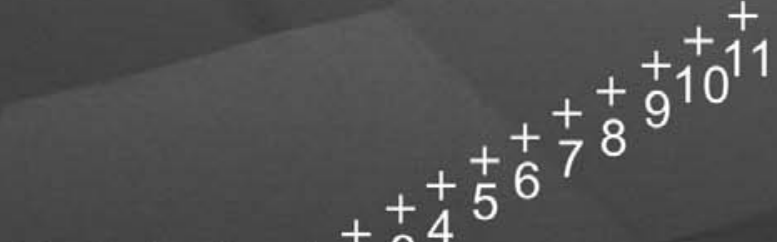

Batch 2 ${ }_{1}^{+}{ }^{+}{ }^{+} 4$

$$
\begin{aligned}
& \text { Batch } 3+++++++++++ \\
& 1234567891011
\end{aligned}
$$

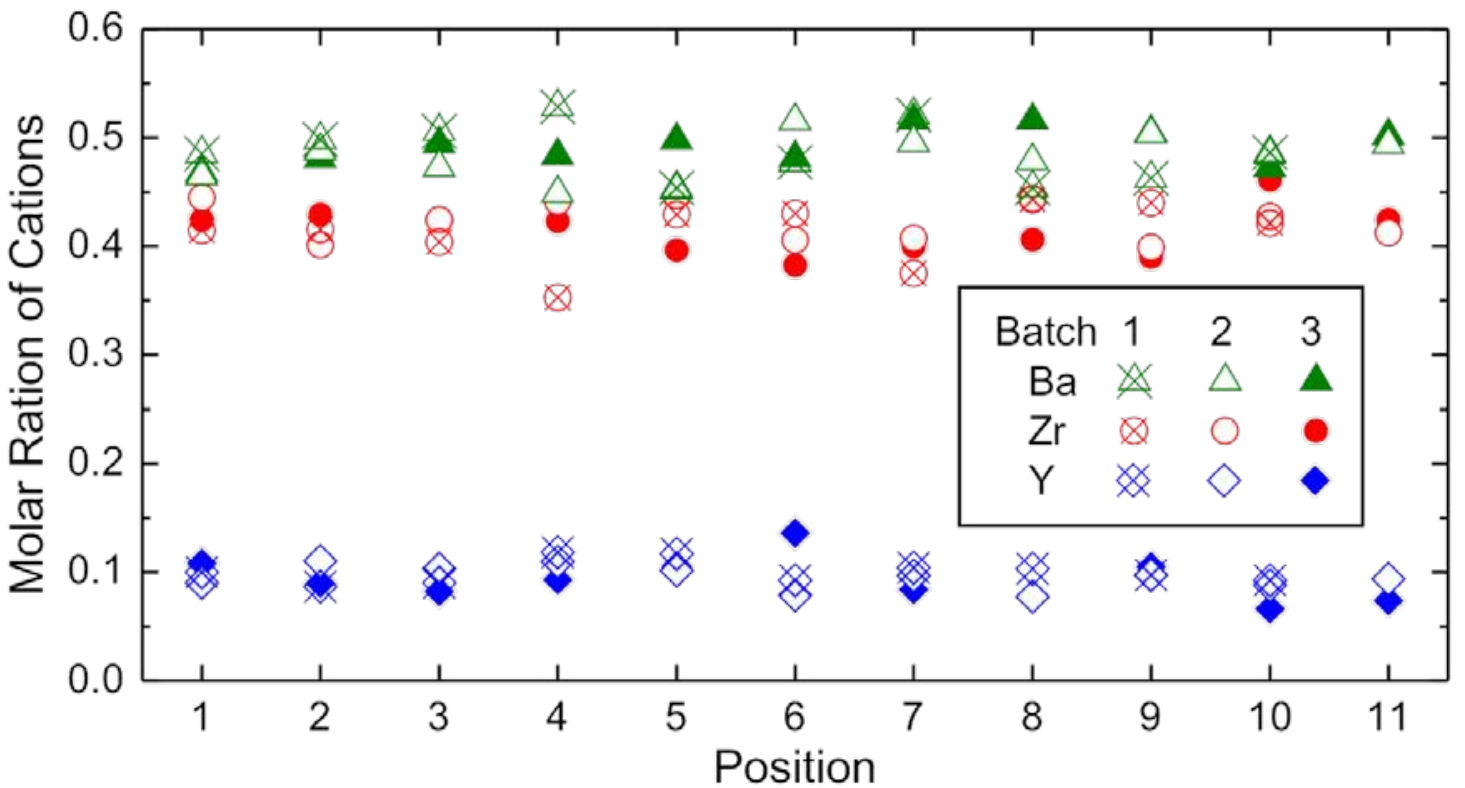

Figure 5 STEM-EDS line scan results of $\mathrm{BaZr}_{0.8} \mathrm{Y}_{0.2} \mathrm{O}_{3-\delta}$ across the grain boundary. 


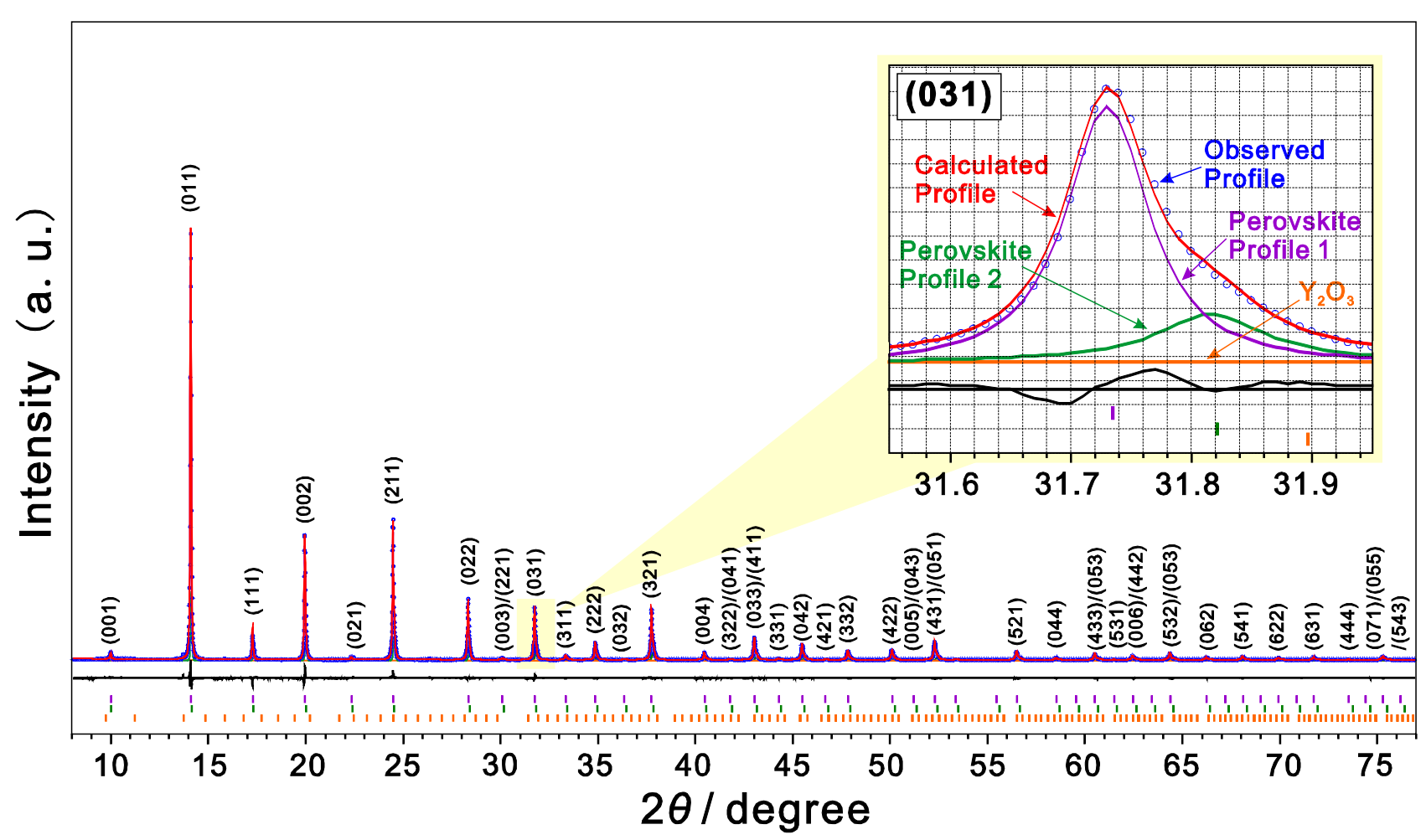

Figure 6 Rietveld refinement of the diffraction pattern of $\mathrm{Ba}_{0.9} \mathrm{Zr}_{0.8} \mathrm{Y}_{0.2} \mathrm{O}_{3-\delta}$, collected with synchrotron radiation $(17.026 \mathrm{keV})$. Two cubic perovskite ( $\mathrm{Pm} \overline{3} \mathrm{~m}$ ) structure models were adopted for the refinement. Fitting of the (031) diffraction peak profile is highlighted in the inset. The observed profile (blue), calculated profile (red), difference (black, at bottom), and Bragg peaks of candidate phases (vertical lines) are shown. 


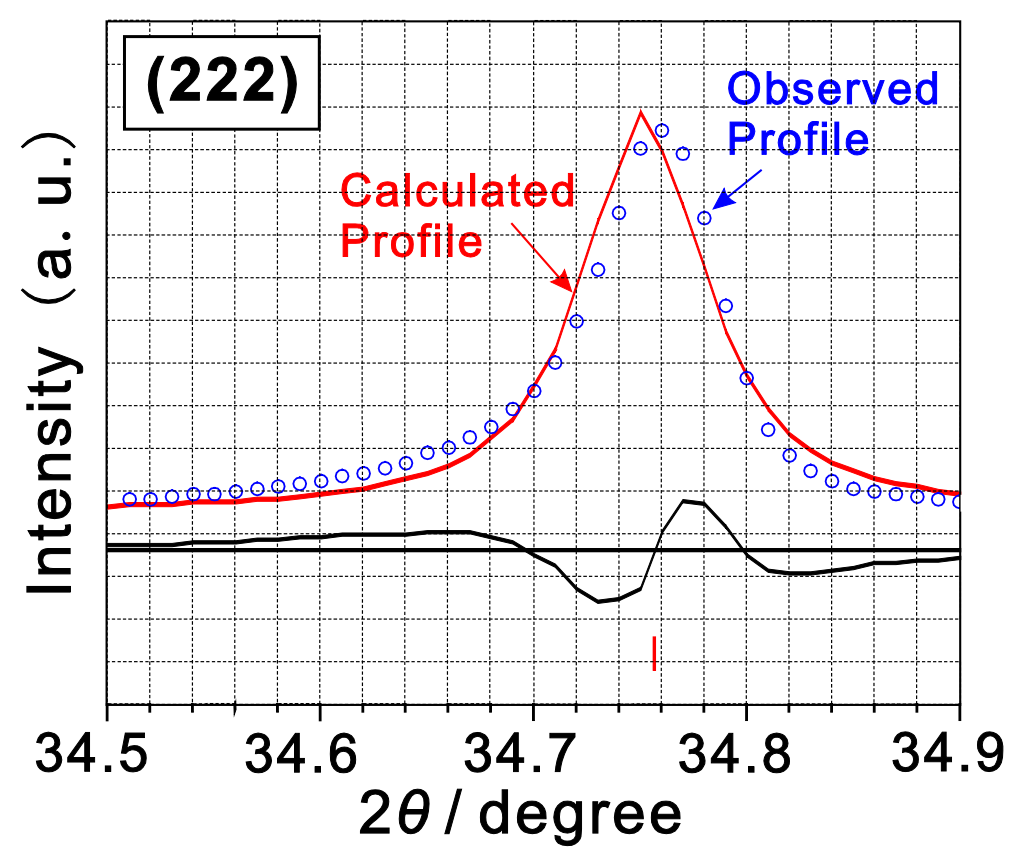

Figure 7 Rietveld refinement of the $(222)^{\mathrm{C}}$ diffraction peak of $\mathrm{BaZr}_{0.8} \mathrm{Y}_{0.2} \mathrm{O}_{3-\delta}$. $\quad(h k l)^{\mathrm{c}}$ indicates Miller indices in the cubic system. The diffraction pattern was collected with synchrotron radiation (17.026 keV). A single tetragonal perovskite $(P 4 / \mathrm{mbm})$ structure model was adopted for this refinement. The observed profile (blue), calculated profile (red), difference (black, at bottom), and Bragg peaks of candidate phases (vertical lines) are shown. The calculated profile is of good symmetry, and is obviously different from the observed profile. 


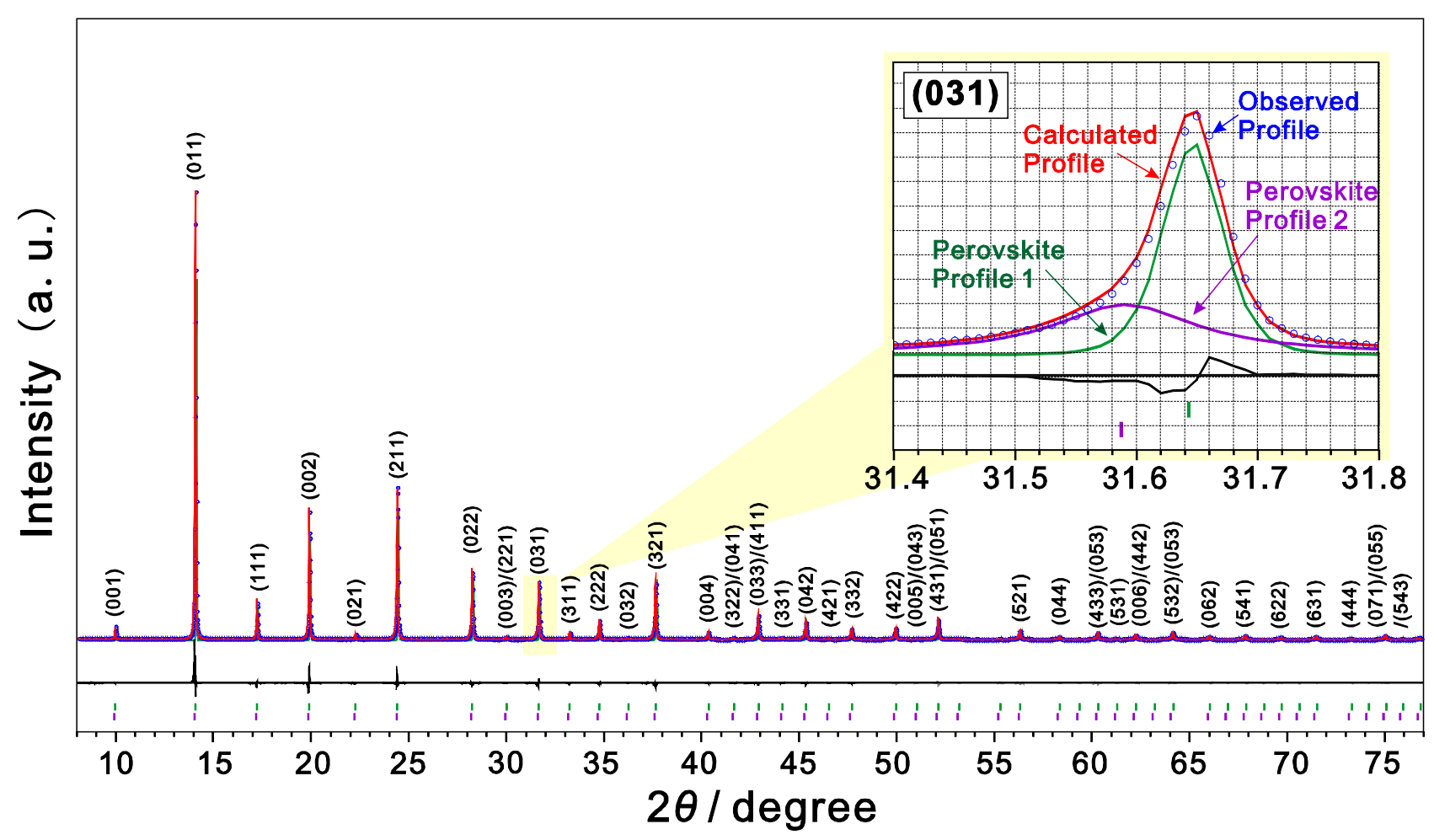

Figure 8 Rietveld refinement of the diffraction pattern of $\mathrm{BaZr}_{0.8} \mathrm{Y}_{0.2} \mathrm{O}_{3-\delta}$, collected with synchrotron radiation $(17.026 \mathrm{keV})$. Two cubic perovskite $(P m \overline{3} \mathrm{~m})$ structure models were adopted for the refinement. Fitting of (031) diffraction peak profile is highlighted in the inset. Observed profile (blue), calculated profile (red), difference (black, at bottom), and Bragg peaks of candidate phases (vertical lines) are shown. 


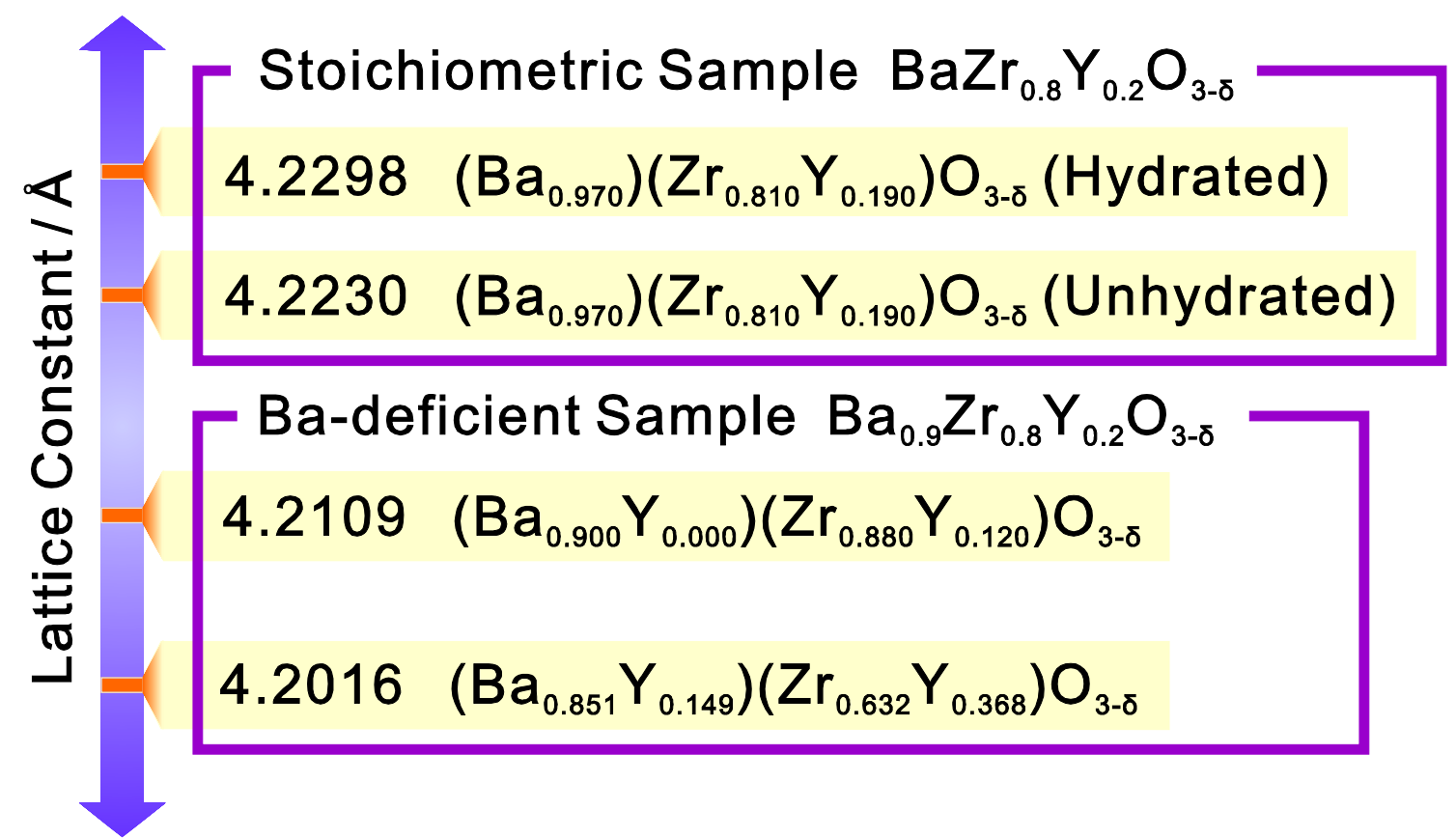

Figure 9 Summary of lattice constant and composition of the perovskite structure models in this study. 
Table 1 Lattice constants and weight fractions of phases in $\mathrm{Ba}_{0.9} \mathrm{Zr}_{0.8} \mathrm{Y}_{0.2} \mathrm{O}_{3-\delta}$ and $\mathrm{BaZr}_{0.8} \mathrm{Y}_{0.2} \mathrm{O}_{3-\delta}$ determined by Rietveld refinement.

\begin{tabular}{|c|c|c|c|c|}
\hline Nominal Sample Composition & Phase (Composition / Method) & Unit Cell & Lattice Constant / $\AA$ & Fraction / wt $\%$ \\
\hline & Major Phase $\left(\mathrm{Ba}_{0.90} \mathrm{Zr}_{0.88} \mathrm{Y}_{0.12} \mathrm{O}_{3-\delta} /\right.$ STEM-EDS $)$ & Cubic $(P m \overline{3} m)$ & $4.2016(15)$ & $76.9(42)$ \\
\hline \multirow[t]{3}{*}{$\mathrm{Ba}_{0.9} \mathrm{Zr}_{0.8} \mathrm{Y}_{0.2} \mathrm{O}_{3-\delta}$} & Minor Phase $\left(\mathrm{Ba}_{0.74} \mathrm{Zr}_{0.55} \mathrm{Y}_{0.45} \mathrm{O}_{3-\delta} /\right.$ STEM-EDS) & Cubic $(\operatorname{Pm} \overline{3} m)$ & $4.2109(1)$ & $16.1(17)$ \\
\hline & Yttria & Cubic $(I a \overline{3})$ & $10.6016(2)$ & $7.0(25)$ \\
\hline & Unhydrated Phase $\left(\mathrm{Ba}_{0.97} \mathrm{Zr}_{0.81} \mathrm{Y}_{0.19} \mathrm{O}_{3-\delta} /\right.$ ICP-AES) & Cubic $(\operatorname{Pm} \overline{3} m)$ & $4.2230(2)$ & $54.0(5)$ \\
\hline \multicolumn{5}{|l|}{$\mathrm{BaZr}_{0.8} \mathrm{Y}_{0.2} \mathrm{O}_{3-\delta}$} \\
\hline & Hydrated Phase ( $\mathrm{Ba}_{0.97} \mathrm{Zr}_{0.81} \mathrm{Y}_{0.19} \mathrm{O}_{3-\delta} /$ ICP-AES) & Cubic $(P m \overline{3} m)$ & $4.2298(7)$ & $46.0(5)$ \\
\hline
\end{tabular}


Table 2 Site occupancy of cations in the phases in $\mathrm{Ba}_{0.9} \mathrm{Zr}_{0.8} \mathrm{Y}_{0.2} \mathrm{O}_{3-\delta}$ and $\mathrm{BaZr}_{0.8} \mathrm{Y}_{0.2} \mathrm{O}_{3-\delta}$ determined by Rietveld refinement. The structures of all the phases were assigned to be cubic ( $P m \overline{3} m)$.

\begin{tabular}{|c|c|c|c|c|c|c|c|c|c|c|}
\hline \multirow{3}{*}{$\begin{array}{l}\text { Nominal Sample } \\
\text { Composition }\end{array}$} & \multirow{2}{*}{$\begin{array}{l}\text { X-ray } \\
\text { Energy }\end{array}$} & \multirow{2}{*}{$\begin{array}{l}R_{\mathrm{wp}} \\
/ \%\end{array}$} & \multirow{3}{*}{$\chi^{2}$} & \multirow{3}{*}{ Phase } & \multicolumn{4}{|c|}{ Site Occupancy } & \multicolumn{2}{|c|}{ Equivalent Isotropic } \\
\hline & & & & & \multicolumn{2}{|c|}{ A-site } & \multicolumn{2}{|c|}{ B-site } & \multicolumn{2}{|c|}{ Temperature Factor / $\AA^{2}$} \\
\hline & / keV & & & & $\mathrm{Ba}$ & $\mathrm{Y}$ & $\mathrm{Zr}$ & $\mathrm{Y}$ & A-site & B-site \\
\hline & 17026 & $C 15$ & 250 & Major Phase $\left(\mathrm{Ba}_{0.90} \mathrm{Zr}_{0.88} \mathrm{Y}_{0.12} \mathrm{O}_{3-\delta}\right)$ & $0.900(2)$ & $0.000(2)$ & $0.880(2)$ & $0.120(2)$ & $0.29(3)$ & $0.76(3)$ \\
\hline & & & & Minor Phase $\left(\mathrm{Ba}_{0.74} \mathrm{Zr}_{0.55} \mathrm{Y}_{0.45} \mathrm{O}_{3-\delta}\right)$ & $0.851(7)$ & $0.149(10)$ & $0.632(5)$ & $0.368(5)$ & $0.50(6)$ & $0.43(7)$ \\
\hline \multicolumn{11}{|l|}{$\mathrm{Ba}_{0.9} \mathrm{Zr}_{0.8} \mathrm{Y}_{0.2} \mathrm{O}_{3-\delta}$} \\
\hline & & & & Major Phase $\left(\mathrm{Ba}_{0.90} \mathrm{Zr}_{0.88} \mathrm{Y}_{0.12} \mathrm{O}_{3-\delta}\right)$ & $0.900(2)$ & $0.000(2)$ & $0.880(2)$ & $0.120(2)$ & $0.37(2)$ & $0.20(2)$ \\
\hline & 16.908 & 6.53 & 4.77 & & & & & & & \\
\hline & & & & Minor Phase $\left(\mathrm{Ba}_{0.74} \mathrm{Zr}_{0.55} \mathrm{Y}_{0.45} \mathrm{O}_{3-\delta}\right)$ & $0.851(8)$ & $0.149(10)$ & $0.632(6)$ & $0.368(6)$ & $0.20(5)$ & $0.20(7)$ \\
\hline & & & & Unhydrated Phase $\left(\mathrm{Ba}_{0.97} \mathrm{Zr}_{0.81} \mathrm{Y}_{0.19} \mathrm{O}_{3-\delta}\right)$ & $0.970(3)$ & $0.000(3)$ & $0.810(2)$ & $0.190(2)$ & $0.80(2)$ & $0.39(2)$ \\
\hline & 17.026 & 7.17 & 4.13 & & & & & & & \\
\hline & & & & Hydrated Phase $\left(\mathrm{Ba}_{0.97} \mathrm{Zr}_{0.81} \mathrm{Y}_{0.19} \mathrm{O}_{3-\delta}\right)$ & $0.970(4)$ & $0.000(5)$ & $0.810(4)$ & $0.190(4)$ & $0.80(5)$ & $0.43(6)$ \\
\hline \multicolumn{11}{|l|}{$\mathrm{BaZr}_{0.8} \mathrm{Y}_{0.2} \mathrm{O}_{3-\delta}$} \\
\hline & & & & Unhydrated Phase $\left(\mathrm{Ba}_{0.97} \mathrm{Zr}_{0.81} \mathrm{Y}_{0.19} \mathrm{O}_{3-\delta}\right)$ & $0.970(2)$ & $0.000(2)$ & $0.810(2)$ & $0.190(2)$ & $0.64(2)$ & $0.20(2)$ \\
\hline & 16.908 & 6.20 & 4.51 & & & & & & & \\
\hline & & & & Hydrated Phase $\left(\mathrm{Ba}_{0.97} \mathrm{Zr}_{0.81} \mathrm{Y}_{0.19} \mathrm{O}_{3-\delta}\right)$ & $0.970(3)$ & $0.000(3)$ & $0.810(3)$ & $0.190(3)$ & $0.52(3)$ & $0.20(4)$ \\
\hline
\end{tabular}


Table 3 Phases in $\mathrm{BaO}-\mathrm{ZrO}_{2}-\mathrm{YO}_{1.5}$ system in literatures.

\begin{tabular}{|c|c|c|c|c|c|c|}
\hline Reporter & Phase & Composition & $\begin{array}{c}\text { Method for } \\
\text { Composition } \\
\text { Determination }\end{array}$ & Structure & Lattice Constant & $\begin{array}{l}\text { Heat-Treating } \\
\text { Temperature }\end{array}$ \\
\hline \multirow[b]{2}{*}{$\begin{array}{l}\text { Oyama } \\
{[22]}\end{array}$} & $\mathrm{BZ}(\mathrm{I})$ & $\begin{array}{l}\text { Solubility of } \mathrm{Y} \text { in } \mathrm{BaZrO}_{3} \text { less than } \\
X_{\mathrm{YO} 1.5}=0.075\end{array}$ & \multirow[b]{2}{*}{ SEM-EPMA } & Cubic & Small & \multirow[b]{2}{*}{$1600{ }^{\circ} \mathrm{C}$} \\
\hline & BZ(II) & $\begin{array}{l}\text { Solid solution between } \mathrm{Ba}_{3} \mathrm{Zr}_{2} \mathrm{YO}_{8.5} \text { and } \\
\mathrm{Ba}_{9} \mathrm{Zr}_{4} \mathrm{Y}_{8} \mathrm{O}_{29}\end{array}$ & & $\begin{array}{l}\text { Cubic with } \\
\text { long range } \\
\text { order supercell }\end{array}$ & Large & \\
\hline \multirow{2}{*}{$\begin{array}{l}\text { Imashuku } \\
\text { [23] }\end{array}$} & $\begin{array}{l}\mathrm{BaZrO}_{3} \\
\text { solid solution }\end{array}$ & $\begin{array}{l}\text { Solubility of } \mathrm{Y} \text { in } \mathrm{BaZrO}_{3} \text { about } X_{\mathrm{YO} 1.5}= \\
0.25\end{array}$ & \multirow{2}{*}{ FESEM-EDS } & Cubic & - & \multirow{2}{*}{$1600{ }^{\circ} \mathrm{C}$} \\
\hline & BZY424 & $\begin{array}{l}X_{\mathrm{BaO}}=0.31-0.40, X_{\mathrm{ZrO} 2}=0.16-0.20 \\
X_{\mathrm{YO} 1.5}=0.42-0.53\end{array}$ & & unknown & - & \\
\hline \multirow{2}{*}{$\begin{array}{l}\text { Azad } \\
{[13]}\end{array}$} & $\begin{array}{l}\alpha \\
\text { (lower protonic } \\
\text { conductivity) }\end{array}$ & $\mathrm{Ba}_{1.01} \mathrm{Zr}_{0.90} \mathrm{Y}_{0.10} \mathrm{O}_{3-\delta}$ & \multirow[t]{2}{*}{ Not measured } & Cubic & Small & \multirow{2}{*}{$\begin{array}{l}1500{ }^{\circ} \mathrm{C} \text { (coexisting of } \alpha \\
\text { and } \beta \text { ) } \\
1720{ }^{\circ} \mathrm{C} \text { (Only } \alpha \text { existed) }\end{array}$} \\
\hline & $\begin{array}{l}\text { (higher protonic } \\
\text { conductivity) }\end{array}$ & $\left(\mathrm{Ba}_{0.985} \mathrm{Y}_{0.015}\right)\left(\mathrm{Zr}_{0.915} \mathrm{Y}_{0.085}\right) \mathrm{O}_{3-\delta}$ & & Cubic & Large & \\
\hline \multirow{3}{*}{$\begin{array}{l}\text { Han } \\
\text { [this } \\
\text { study] }\end{array}$} & $\begin{array}{l}\mathrm{BaZr}_{0.8} \mathrm{Y}_{0.2} \mathrm{O}_{3-\delta} \\
\text { major phase }\end{array}$ & $\mathrm{Ba}_{0.97} \mathrm{Zr}_{0.81} \mathrm{Y}_{0.19} \mathrm{O}_{3-\delta}$ & \multirow{3}{*}{ STEM-EDS } & Cubic & - & \multirow{3}{*}{$1600{ }^{\circ} \mathrm{C}$} \\
\hline & $\begin{array}{l}\mathrm{Ba}_{0.9} \mathrm{Zr}_{0.8} \mathrm{Y}_{0.2} \mathrm{O}_{3-\delta} \\
\text { major phase }\end{array}$ & $\mathrm{Ba}_{0.90} \mathrm{Zr}_{0.88} \mathrm{Y}_{0.12} \mathrm{O}_{3-\delta}$ & & Cubic & Large & \\
\hline & $\begin{array}{l}\mathrm{Ba}_{0.9} \mathrm{Zr}_{0.8} \mathrm{Y}_{0.2} \mathrm{O}_{3-\delta} \\
\text { minor phase }\end{array}$ & $\mathrm{Ba}_{0.74} \mathrm{Zr}_{0.55} \mathrm{Y}_{0.45} \mathrm{O}_{3-\delta}$ & & Cubic & Small & \\
\hline
\end{tabular}


Tables of Contents Entry

Text:

Tendency of $\mathrm{Y}$ occupying B-site in $\mathrm{BaZrO}_{3}$ with high Ba-deficiency and $\mathrm{Y}$ content confirmed by

precise Rietveld refinement benefit from anomalous dispersion effect.

Colour graphic:

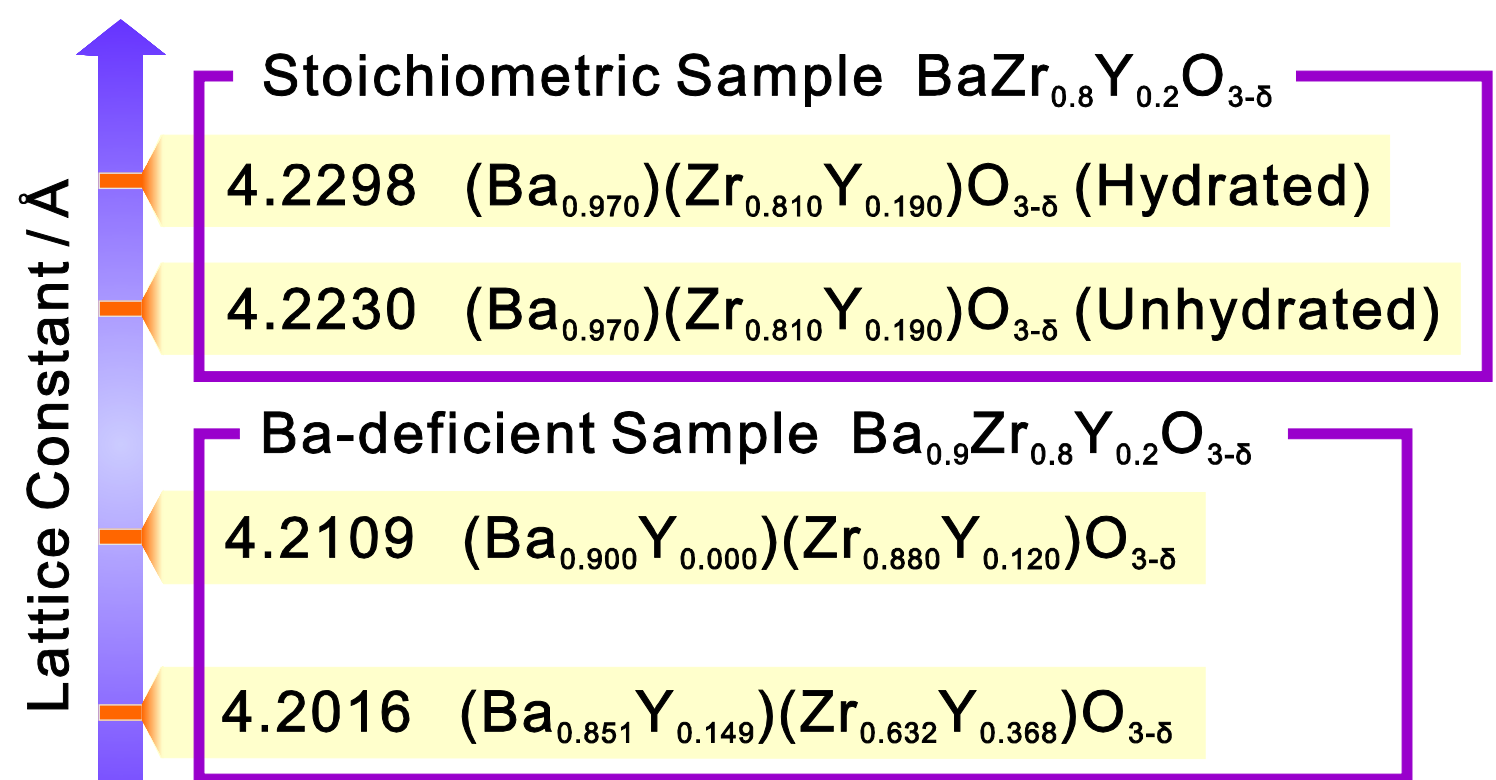

